\title{
HYPNOBREASTFEEDING DAPAT MENURUNKAN KECEMASAN PADA IBU POST PARTUM
}

\author{
Lutfiana Puspita Sari $^{1}$, Harsono Salimo ${ }^{2}$, Uki Retno Budihastuti ${ }^{3}$ \\ ${ }^{1}$ Poltekkes Kemenkes Surakarta Jurusan Kebidanan \\ ${ }^{2}$ Departemen Pediatric, RSUP Dr. Moewardi Surakarta \\ ${ }^{3}$ Departemen Obstetri dan Gynekologi, RSUP Dr. Moewardi Surakarta \\ Diterima : 7 Januari 2019, Disetujui : 4 Februari 2019
}

\begin{abstract}
Background: Post partum period is condition of a time that very influential on the psychological and social conditions for women after giving birth. The incidence of post partum blues increased in this period of time with a prevalence of $30 \%$ to $75 \%$. Post partum blues give effect to the early cessation of breastfeeding process which is contribute to child mortality under 5 years of $11.6 \%$. This is associated with the practice of exclusive breastfeeding that are not optimal as a result of post partum blues experienced by woman after giving birth. The purpose is to analyze the anxiety in the group given the Hypnobreastfeeding intervention treatment and which is not given the intervention treatment, held at RSUP Dr. Suradji Tirtonegoro, Klaten. Method: Research is experimental design with randomized control trial. The population is all pregnant women in Puskesmas Jogonalan I area of Klaten. A total of 60 post partum object was selected for this study by simple random sampling. This was a randomized controlled trial, conducted at RSUP Dr. Suradji Tirtonegoro, Klaten. Results: The difference of dependent variables between the two groups were tested by MannWhitney. Conclusion: There is a differences and significance level of result of degree of anxiety between both treatment result with $p=0.002$. Hypnobreastfeeding intervention treatment can relief anxiety level for post- partum mother
\end{abstract}

Keywords: Anxiety, Hypnobreastfeeding, Post Partum mother.

\section{PENDAHULUAN}

Kehamilan, bersalin, dan nifas merupakan periode yang sangat berpengaruh terhadap kondisi psikologi maupun sosial pada wanita. Pada periode ini, setiap wanita lebih berisiko untuk mengalami gangguan mood, salah satunya adalah post partum blues/baby blues (WHO, 2008). Wanita yang mengalami post partum blues akan mengalami gangguan terhadap niat, motivasi, efikasi diri dan proses maupun durasi dalam menyusui.

Salah satu tanda dari post partum blues adalah kecemasan dan merupakan salah satu faktor risiko yang berpengaruh terhadap berhentinya proses menyusui lebih dini (Demilade et al, 2014). Berdasarkan analisis yang terbaru menunjukkan bahwa praktik menyusui yang tidak optimal termasuk tidak memberikan ASI ekslusif menyumbang kematian pada anak dibawah 5 tahun sebesar 11.6\% (WHO, 2014).

Berdasarkan data dari WHO (2008) prevalensi kejadian post partum blues di dunia 30-75\% dan ini berlangsung selama 3-4 hari dan memuncak pada hari ke lima post partum (Thurgood et al, 2009). Tidak ada data yang pasti mengenai jumlah 
kejadian post partum blues di Indonesia karena tidak terlaporkan dengan baik. Berdasarkan Depkes RI (2008) satu dari 10 wanita yang baru saja melahirkan di Indonesia memiliki kecenderungan mengalami post partum blues (Miyansaski et al, 2014).

Salah satu penyebab utama terjadinya post partum blues adalah adanya ketidakseimbangan hormon yaitu hormon estrogen, progesteron, prolactin dan estriol yang fluktuatif setelah melahirkan sehingga hal ini berpengaruh terhadap suasana hati diantaranya adalah kecemasan (Ahmad et al, 2015). Kecemasan jika tidak segera ditangani akan berkembang menjadi depresi post partum dan memberikan efek yang lebih buruk baik terhadap ibu maupun bayi.

Ibu yang mengalami depresi post partum menyumbangkan tingginya angka kegagalan bayi yang diberikan ASI ekslusif di Indonesia. Hormon stres yaitu kortisol akan menghambat sekresi hormon prolaktin dan oksitosin sehingga produksi ASI secara tidak langsung akan berkurang dan ibu merasa ASI nya tidak cukup untuk memenuhi kebutuhan bayi. Untuk efek jangka panjang, anak-anak yang dilahirkan dari ibu yang mengalami depresi post partum akan mengalami masalah terhadap perkembangan social/interpersonal dan perilaku (Stewart et al, 2003).

Intervensi yang dapat dilakukan supaya kejadian kecemasan yang dialami pada ibu post partum tidak berkembang menjadi depresi post partum salah satunya dengan melakukan relaksasi. Teknik relaksasi merupakan metode, prosedur, proses, kegiatan untuk membantu seseorang agar tercapai kondisi yang lebih rileks, tenang, mengurangi kecemasan dan stres (El-Aziz et al, 2016).
Relaksasi digunakan dalam managemen stres yang bermanfaat untuk menurunkan ketegangan otot, tekanan darah, detak jantung, dan pernafasan. Dengan melakukan relaksasi secara rutin maka akan dapat meningkatkan fungsi otak serta aliran udara yang cukup melalui saluran pernafasan sehingga akan merasakan ketenangan dan relaks (El-Aziz et al, 2016).

Relaksasi dapat tercapai salah satunya dengan hypnosis. Hypnosis yang digunakan untuk mengurangi kecemasan pada ibu post partum dan untuk melancarkan produksi ASI sering disebut dengan hypnobreastfeeding. Teknik rileksasi hypnobreastfeeding adalah cara atau metode terbaru yang sangat baik untuk membangun niat positif dan motivasi dalam menyusui serta mampu memaksimalkan kuantitas dan kualitas ASI (Andriana, 2007).

Penelitian terkait dengan pengaruh relaksasi terhadap kecemasan sudah banyak dilakukan. Keterbaruan penelitian ini adalah merupakan pengembangan dari konsep hypnobirthing (relaksasi untuk proses persalinan agar aman, mudah, dan nyaman) yang sudah dipraktikkan sejak tahun 1950-an oleh Mongan di Amerika serikat. Relaksasi pada penelitian ini menggunakan hypnobreastfeeding yang diterapkan kepada ibu menyusui agar kecemasan menurun, ibu dapat relaks, tenang sehingga proses produksi ASI berlangsung dengan baik. Tujuan umum penelitian ini adalah untuk menganalisis perbedaan kecemasan pada kelompok yang diberikan intervensi hypnobreastfeeding dengan yang tidak diberikan intervensi hypnobreastfeeding . 


\section{METODE PENELITIAN}

Penelitian ini termasuk jenis penelitian eksperimen analitikal observasional dengan pendekatan randomized control trial (RCT). Desain yang digunakan adalah completely randomized experimental design. Metode RCT ini termasuk salah satu keterbaruan dalam penelitian ini dari sisi metode penelitian yng digunakan.

Populasi pada penelitian ini adalah seluruh ibu post partum yang bersalin di RSUP Dr. Suradji Tirtonegoro Klaten dan sedang menjalani rawat gabung dalam 48 jam pertama pada bulan Januari-Maret 2017. Teknik pengambilan sampel dengan cara randomisasi (simple random sampling). Perhitungan besar subjek penelitian ini menggunakan "rule of thumb" yaitu subjek penelitian minimal 30 orang subjek untuk masing-masing kelompok (Murti, 2013). Penelitian ini menggunakan 60 sampel dengan klasifikasi masing-masing 30 subjek penelitian pada kelompok Hypnobreastfeeding maupun kontrol. Subjek penelitian semua ibu post partum pada 48 jam pertama baik primi maupun multi dan bersalin dengan spontan maupun section secarea semua mendapat kesempatan yang sama untuk terpilih ke dalam kelompok intervensi dan yang menentukan hanya faktor peluang.

Untuk subjek dengan riwayat persalinan spontan, hypnobreastfeeding dilakukan pada 24 jam pertama post partum, sedangkan pada subjek dengan riwayat persalinan section secarea dilakukan pada 24 jam kedua, hal ini dikaitkan dengan kondisi fisik maupun psikis yang berbeda pada subjek dengan persalinan spontan dan section secarea.

Pengumpulan data, untuk mengukur kecemasan pada ibu post partum menggunakan skala STAI (The Spielberger State and Trait Anxiety Inventory). STAI merupakan alat ukur yang sudah valid digunakan untuk menilai kecemasan dan divalidasi untuk digunakan pada populasi perinatal yaitu mulai trimester tiga pada saat kehamilan hingga 2 sampai 8 minggu kunjungan nifas. Alat ukur ini mengukur secara terpisah yaitu kecemasan sesaat (A-state) dan kecemasan dasar (A-trait) (Stuebe et al, 2013 \& Cox et al, 2015)

Kecemasan dikategorikan menjadi rendah dan tinggi. Jika hasil STAI $\leq 40$ maka termasuk kategori kecemasan rendah, namun jika hasil STAI > 40 termasuk kategori kecemasan tinggi. Hypnobreastfeeding dilakukan pada 48 jam pertama post partum.

\section{HASIL PENELITIAN}

Hasil karakteritistik subjek penelitian pada tabel 1 menunjukkan dari 30 subjek penelitian dalam kelompok intervensi dan 30 kelompok kontrol. Deskripsi variabel penelitian dijelaskan berdasarkan karakteristik, kriteria, frekuensi, dan persentase. Pada kelompok intervensi maupun kontrol sebagian besar responden berusia 20-35 tahun, untuk kelompok intervensi 26 responden (86.7\%), dan kelompok kontrol sebesar 23 responden $(76.7 \%)$.

Sebagian besar subjek penelitian untuk kelompok intervensi berpendidikan SD-SMP 16 responden (53.3\%), dan kelompok kontrol sebagian besar yaitu 22 responden $(73.3 \%)$ berpendidikan SMAPerguruan Tinggi. Untuk paritas sebagian besar responden merupakan paritas multi (pernah melahirkan lebih dari $1 \mathrm{x}$ ) pada kelompok intervensi sebanyak 19 responden $(63.3 \%)$, dan pada kelompok kontrol sebanyak 18 responden $(60 \%)$. 
Untuk LILA sebagian besar responden memiliki LILA $\geq 23.5$ pada kelompok intervensi dan kontrol masingmasing sebanyak 28 responden (93.3\%), untuk jenis persalinan sebagian besar responden mengalami persalinan spontan, pada kelompok intervensi sebanyak 20 responden (66.7\%), dan pada kelompok kontrol sebesar 21 responden $(70 \%)$.

Tabel 1. Karakteristik Subjek Penelitian

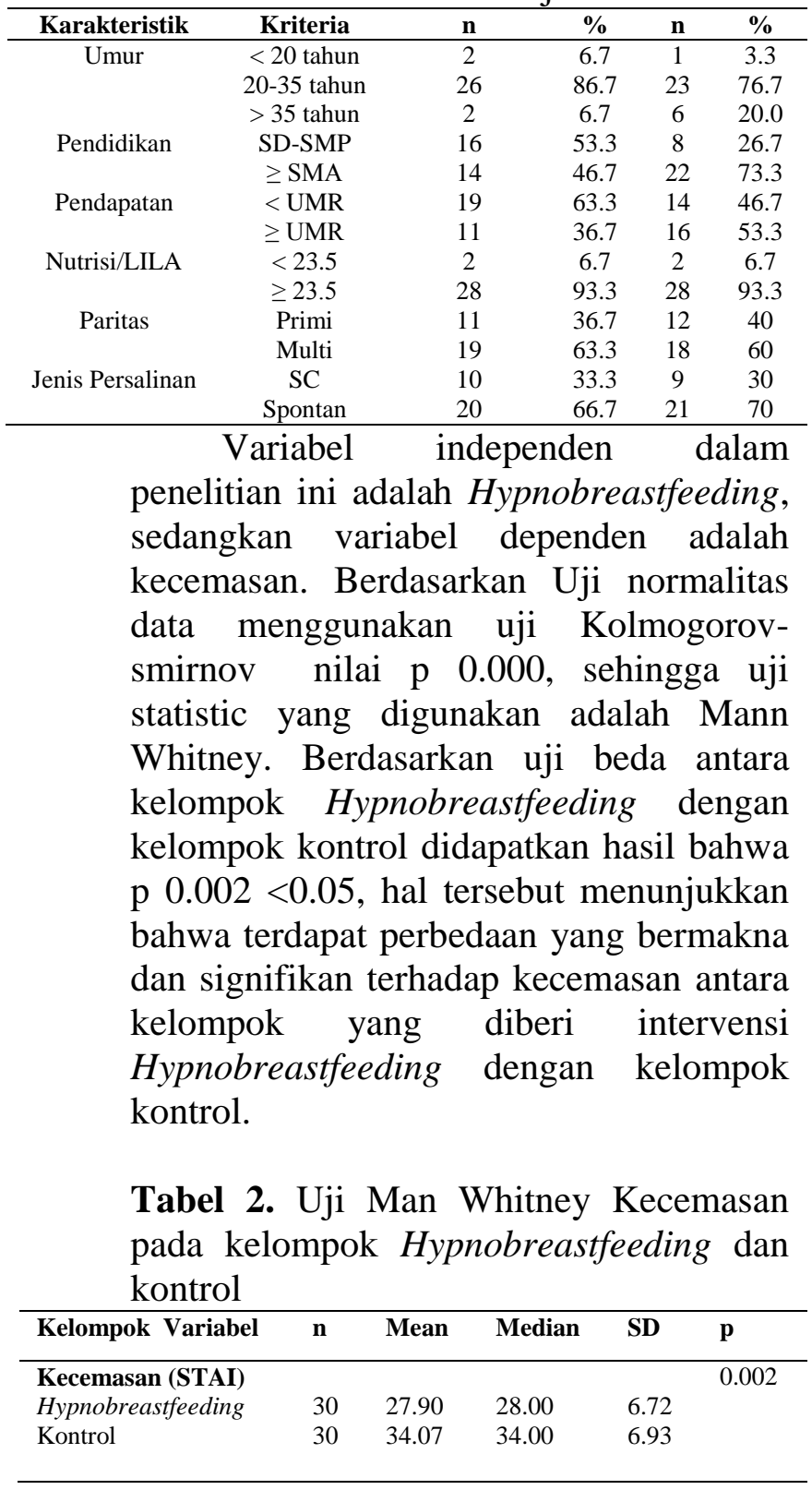

\section{PEMBAHASAN}

Hasil penelitian menunjukkan bahwa terdapat perbedaan yang bermakna dan signifikan terhadap kecemasan antara kelompok yang diberikan intervensi hypnobreastfeeding dengan yang tidak diberikan intervensi hypnobreastfeeding. Hal ini sesuai dengan penelitian yang dilakukan oleh Araujo, et al (2016) bahwa relaksasi efektif menurunkan tingkat kecemasan pada ibu hamil dengan risiko tinggi setelah diterapkan relaksasi salama 5 hari yang dinilai tingkat kecemasan sebelum dan sesudah dilakukan rileksasi (Araujo et al, 2016).

Penelitian yang sama juga telah dilakukan oleh Toosi et al (2014) dengan hasil bahwa terdapat perbedaan yang signifikan terhadap kecemasan ibu antara kelompok yang diberikan intervensi relaksasi dengan yang tidak diberikan intervensi, dengan nilai p 0.017 .

Ada 3 prinsip dasar dalam obstetric untuk mengurangi rasa sakit dan kecemasan. Relaksasi merupakan metode non farmakologi yang paling efektif untuk menurunkan kecemasan karena terapi ini sangat sederhana, mudah, aman, dan nyaman. Selain itu relaksasi memberikan dampak dapat menurunkan denyut jantung dan tekanan darah sistolik dan diastolik, memperlancar peredaran darah dan pernafasan sehingga memberikan efek ketenangan bagi ibu (Toosi et al, 2014 \& Procelli et al, 2005).

Intervensi relaksasi menginduksi keadaan relaksasi yang merupakan respon fisiologis dalam tubuh yang berlawanan dengan respon stres. Respons relaksasi, ditimbulkan melalui berbagai teknik relaksasi sehingga mengurangi aktivitas sistem saraf simpatik dan, dengan demikian, mengimbangi respon stres. 
Respon relaksasi secara bersamaan mengaktifkan sistem saraf parasimpatik, menghasilkan penurunan ketegangan otot metabolisme dan peningkatan efek menenangkan dan suasana hati yang menyenangkan sehingga ibu post partum yang memiliki suasana hati tenang dan nyaman akan berpengaruh terhadap produksi ASI yang dihasilkan. Namun, tidak semua ibu post partum mengalami kenyamanan, bahagia dan senang pasca melahirkan.

Inti dalam melakukan hypnosis adalah relaksasi, focus untuk berfikir dan melakukan visualisasi, serta menanamkan sugesti dan harapan sehingga terwujud dalam sikap dan tingkah laku sehari-hari (Golden, 2012).

Ibu post partum yang melakukan hypnosis dan relaksasi dengan cara menanamkan sugesti dan melakukan visualisasi serta harapan yang diinginkan maka segala kecemasan dan stres yang dialami akan berkurang. Hal ini disebabkan hormone kortisol yang berpengaruh terhadap stres dihambat proses pengeluarannya oleh aktifnya syaraf para simpatis sehingga yang keluar adalah hormon oksitosin dan endorphin. Ibu merasakan ketenangan, nyaman, dan kebahagiaan.

Relaksasi pada ibu menyusui yang sering disebut dengan relaksasi hypnobreastfeeding merupakan teknik relaksasi dengan melakukan kontak langsung dengan alam bawah sadar. Ketika mampu mencapai kondisi relaks yang dalam dan stabil, maka akan mampu menanamkan suatu program atau konsep baru yang secara otomatis akan mempengaruhi kehidupan dan tindakan sehari-hari tanpa disadari dalam hal ini menanamkan sugesti kepercayaan diri menjadi seorang ibu dan mampu menjaga serta merawat bayinya dengan baik serta dapat memberikan nutrisi yang terbaik untuk bayi.

Dasar hipnobreastfeeding adalah pemanfaatan kemampuan untuk mengakses alam bawah sadar secara langsung, karena alam bawah sadar adalah otak yang sesungguhnya yang menjalankan kehidupan, mengatur tindakan atau apapun yang dilakukan setiap hari (Andriana, 2007).

Keberhasilan dari relaksasi adalah ibu mampu melakukan self hypnosis. Terapis belum tentu dapat selalu mendampingi selama proses relaksasi, sehingga ibu diajarkan untuk melakukan induksi hypnosis, teknik pendalaman relaksasi, dan menanamkan sugesti hypnosis. Ibu diajarkan bagaimana menggunakan self-hypnosis untuk mempersiapkan diri mereka sendiri menghadapi situasi yang menimbulkan kecemasan.

Selama self-hypnosis, ibu dilatih untuk membayangkan mengatasi stres yang akan datang dan menamankan sugesti hypnosis untuk mengurangi kecemasan dan membangun kepercayaan diri. Sehingga ketika self hypnosis dilakukan secara terus menerus maka segala kecemasan yang dialami ibu post partum akan berkurang. Self hypnosis sebagai sarana untuk mengatasi stress/ kecemasan yang dialami oleh ibu (Ali, 2010\&Golden, 2012).

Relaksasi juga terbukti untuk membantu dalam mengelola waktu tidur, mengurangi kegugupan, dan mampu mengontrol keinginan sehingga ketika pikiran relaks maka akan mampu memanfaatkan waktu dengan kegiatan yang lebih positif sehingga stres dan kecemasan berkurang. 
Hal ini sesuai dengan hasil penelitian Ali (2010) terdapat hubungan yang signifikan untuk kecemasan dan depresi antara kelompok yang diberikan intervensi relaksasi dengan kelompok kontrol. Sehingga kelompok yang diberikan intervensi relaksasi mengalami penurunan yang drastis untuk kecemasan dan depresi, pengurangan ketegangan otot,nyeri, gangguan tidur dan memulihkan metabolisme lainnya dalam tubuh (Ali, 2010).

Relaksasi hypnobreastfeeding dapat dilakukan sejak trimester tiga pada saat kehamilan. Hal ini dapat digunakan sebagai sarana untuk berkomunikasi dengan bayi serta mempersiapkan proses persalinan dan dapat mengurangi rasa nyeri ketika proses persalinan berlangsung.

Berdasarkan hasil systematic review beberapa penelitian dilaporkan bahwa ibu yang telah melakukan relaksasi sejak kehamilan maka akan dapat melalui proses persalinan dengan santai, nyaman dan lebih siap untuk menjadi ibu ketika bayi sudah dilahirkan. Selain itu, juga dapat menurunkan risiko terjadinya depresi pasca melahirkan (James, 2009).

\section{KESIMPULAN DAN SARAN}

Relaksasi hypnobreastfeeding efektif untuk menurunkan kecemasan baik dimulai dari kehamilan hingga post partum. Hasil analisis dengan Man Whitney memperlihatkan ada perbedaan yang bermakna terhadap kecemasan ibu post partum antara kelompok yang diberikan intervensi rileksasi hypnobreastfeeding dengan kelompok yang tidak diberikan hypnobrestfeeding.

Karakteristik subjek penelitian tersebar merata di seluruh kelompok, sehingga faktor paritas dan jenis persalinan tidak menjadi faktor perancu terhadap hasil penelitian.

Saran yang diberikan sesuai dengan hasil penelitian ini adalah, Relaksasi Hypnobreastfeeding dapat dilakukan di semua fasilitas pelayanan kesehatan, sehingga terapi ini dapat dijadikan program dalam kelas ibu sejak dari kehamilan. Mengadakan pelatihan bagi tenaga kesehatan yang belum mendapatkan pelatihan terkait dengan relaksasi hypnobreastfeeding sehingga dapat mengaplikasikan kepada semua pasien sejak program hamil pada kelas ibu hamil sehingga tidak ada lagi ibu post partum yang mengalami kecemasan atau post partum blues yang akan berdampak terhadap produksi ASI yang dihasilkan.

Ibu hamil trimester III sebaiknya sudah mulai dilatih selain program untuk management nyeri pada saat persalinan juga diperkenalkan untuk hypnobreastfeeding sehingga sudah siap setelah melahirkan. Program ini memerlukan dukungan semua pihak termasuk dinas kesehatan, tenaga kesehatan dan stakeholder lainnya.

Untuk penelitian selanjutnya dalam mengukur kecemasan tidak hanya menggunakan skala/parameter kecemasan yang sudah baku melainkan dapat mengukur kecemasannya melalui kadar hormon kortisol sehingga mendapatkkan hasil yang lebih akurat mengenai kadar kecemasan dari masing-masing ibu post partum.

\section{DAFTAR RUJUKAN}

Ahmad M, Maryam SB, Bilal U, Hafiz SA, Nayab I, Umer M (2015). Prevalence of depression in an urban setting. Biomedical research. 2015; 26(4) : 765-770 
Ali U (2010), The effectiveness of relaxation therapy in the reduction of anxiety related symptoms (case study). International journal of psychological studies. Vol 2. No.2

Andriana E (2007). Melahirkan Tanpa Rasa Sakit Dengan Metode Hypnobirthing. Jakarta : Buana Ilmu Populer

Araujo WS , Walckiria GR, Eliana Z, Maria HCA (2016). Effects of relaxation on depression levels in women with high-risk pregnancies : a randomized clinical trial. Revista latino - Americana de Enfermagem. 2016; 24 :e2806

Cox EQ, Stuebeb A, Pearsona B, Grewena $\mathrm{K}$, Rubinowa D, and Meltzer BS (2015). Oxytocin and HPA stress axis reactivity in postpartum women.

Psychoneuroendocrinology.

55:164-172

Demilade A, Adedinsewo, Alison SF, Meir S, Michael J, et al (2014). Maternal Anxiety and Breastfeeding: Findings from the MAVAN (Maternal Adversity, Vulnerability and Neurodevelopment) Study. Journal of Human Lactation 2014, Vol 30(1) : 102-109

El-Aziz KSA and Ahmad MM (2016). Effect of Relaxation Exercises on Postpartum Depression. International Journal of PharmTech Research. 2016 ; Vol.9. No 3 : pp 09-17

Golden WL (2012). Cognitive Hypnoteraphy For Anxiety Disorders. American Journal Of Clinical Hypnosis. 54: 263-274 https://www.tandfonline.com/doi/a $\underline{\mathrm{bs} / 10.1080 / 00029157.2011 .65033}$
James $\stackrel{3}{U}$ (2009). Practical uses of clinical hypnosis in enhancing fertility, healthy pregnancy and childbirth. Complementer Therapies in Clinical Practice. 15 (2009) 239241

https://www.sciencedirect.com/science/art icle/pii/S1744388109000991

Miyansaski AU, Misrawati, Febrina S (2014). Perbandingan Kejadian Post Partum Blues Pada Ibu Post Partum Dengan Persalinan Normal dan Sectio Caesarea. JOM PSIK Vol.1 No.2

Murti, B (2013). Desain Dan Ukuran Sampel Untuk Penelitian Kuantitatif Dan Kualitatif Di Bidang Kesehatan. Yogyakarta : Gadjah Mada University Press

Procelli DA (2005). The effect of music theraphy and rilexation prior to breastfeeding on the anxiety of new mothers and the behavior state of their infants during feeding. [Thesis] : Florida state University

Shah LBI, Piyanee KY, Samantha T, Premarani K (2014). Efficacy of Psychoeduaction and relaxation intervention on stress - related variables in people with mental disorders : A literature review. Archives of psychiatric nursing.28 (2014) 94-101. https://www.ncbi.nlm.nih.gov/pub med/24673782

Stewart DE, Robertson E, Dennis CL, Grace SL, Wallington T (2003). Postpartum depression : literature review of risk factors and interventions. Toronto public health.

Stuebe AM, Karen G, Samantha MB (2013). Association Between 
Maternal Mood and Oxytocin

Response to Breastfeeding. Journal of women's health. Volume 22 : Number 4, 2013.

Thurgood S, Daniel MA, Loyda W (2009). Postpartum Depression. American Journal of Clinical Medicine. Spring. 2009; Vol six : Number two

Toosi M, Marzieh A, Farkhondeh S, Najaf $\mathrm{Z}$ (2014). The reduction of anxiety and improved maternal attachment to fetuses and neonates by relaxation training in primigravida women. Women's health bulletin. 2014; 1(1): e18968

Wold Health Organization (2008). Maternal Mental Health \& Child Health and Development. Literature review of risk factors and interventions on Postpartum Depressions. Available from: http://www.who.int/mental_health/ prevention/suicide/mmh\&chd_cha pter_1.pdf 